\title{
The human biomonitoring of occupational exposure to phthalates
}

\author{
Ida Petrovičová \\ Branislav Kolena \\ Tomáš Pilka \\ Constantine the Philosopher University in Nitra, \\ Department of Zoology and Anthropology, \\ Nábrežie mládeže 91, 949 74, Nitra, Slovakia \\ ipetrovicova@ukf.sk
}

\section{DOI:10.5901/mjss.2014.v5n19p101}

\begin{abstract}
Phthalates like endocrine disrupting compounds are ubiquitous environmental contaminants. Long term exposure to these chemicals at the work place has adverse effect on human health and usually leads to diseased conditions. The aim of our study was to assess, by biological monitoring, occupational exposure to di-(2-ethylhexyl) phthalate (DEHP), di-n-butyl phthalate (DnBP), diethyl phthalate (DEP) and diisononyl phthalate (DiNP) of occupationally exposed group i.e. workers from plastic manufactory with division of films and composites and injection moulding ( $n=37$; average age 45.6 \pm 9.4 ) in comparison with general population i.e. students and workers from Constantine the Philosopher University in Nitra ( $n=144$; average age $28 \pm 13.12$ ) in Nitra region of Slovakia. In response to determine human exposure to phthalates, we used high performance liquid chromatography and tandem mass spectrometry analysis (HPLC-MS/MS) to estimate trace levels of 4 phthalate metabolites mono-(2-ethylhexyl) phthalate (MEHP), monoisononyl phthalate (MiNP), mono-n-butyl phthalate (MnBP) and monoethyl phthalate (MEP) in human urine. Median concentrations of the urinary metabolites in the exposed group were $35.48 \mu \mathrm{g} / \mathrm{l}$ for MEHP, $13.65 \mu \mathrm{g} / \mathrm{l}$ for MiNP, $93.79 \mu \mathrm{g} / \mathrm{l}$ for MEP, $108.62 \mu \mathrm{g} / \mathrm{l}$ for MBP and in general population were 21.62 $\mu \mathrm{g} / \mathrm{l}$ for MEHP, $13.26 \mu \mathrm{g} / \mathrm{l}$ for MiNP, 84.36 for $\mu \mathrm{g} / \mathrm{l} \mathrm{MEP}$ and $88.99 \mu \mathrm{g} / \mathrm{l}$ for MBP. We observed, significantly higher urinary concentration $(p \leq 0.001)$ of MEHP and on the border of the statistical significance urinary concentration of MiNP $(p=0.07)$ in occupationally exposed group. Despite the fact that phthalates are ubiquitous environmental contaminants, there is evidence of occupational exposure of workers from plastic manufactory by DEHP a DiNP. This study was supported by project VEGA (V1/0042/12).
\end{abstract}

Keywords: Biomonitoring, MEHP, MiNP, MBP, MEP, Occupational Exposure

\section{Introduction}

Phthalates (dialkyl or alkyl aryl esters of phthalic acid) are group of chemicals widely used to render plastics soft and flexible. High-molecular weight phthalates, such as di-(2-ethylhexyl) phthalate and diisononyl phthalate (DiNP) primarily used as plasticizers in polyvinyl chloride (PVC) can be found in building materials, floorings, cables and wires, furnishing, car interiors, toys, medical devices and food packaging (Blount et al., 2000; David et al., 2005; Loff et al., 2007; Wittassek et al., 2011). Low-molecular weight phthalates, such as diethyl phthalate (DEP) and di-n- butyl phthalate (DnBP) are often used in personal care product, solvents, adhesives or enteric-coated tablets (Hauser \& Calafat, 2005; Heudorf et al., 2007; Wittassek et al., 2011).

Phthalates are not covalently bound to PVC they can leach, migrate or evaporate into indoor air and atmosphere, foodstuff and other materials leads to human exposure (contamination) via inhalation, ingestion and dermal contact (Heudorf et al., 2007). Upon exposure, phthalates are rapidly metabolized to their corresponding hydrolytic monoesters, while DEHP and other higher molecular weight phthalates are further metabolized to several oxidative metabolites. (Koch et al., 2004, 2005; Koch \& Angerer, 2007). Monoester and oxidative metabolites may be glucuronidated before excretion and subsequently excreted in urine, faeces (Silva et al., 2003). The content of phthalate metabolites in human urine represents a measure of the exposure of parent diester occurred within the last 24 hour however some phthalates (i.e. oxidized metabolite of DEHP) have been shown to have half-life elimination longer than 24 hour (Koch et al., 2005). 
Recently, public health concerns have emerged about the toxic qualities of substances contained in consumer plastics and their potential impact on human health. Workers employed in the plastics industry are exposed to a numerous of toxic chemicals used in plastics production. These include styrene, acrylonitrile, vinyl chloride, phthalates, bisphenol-A (BPA), brominated flame retardants, heavy metals, and complex chemical mixtures (DeMatteo et al.,2012). Many of these additives have potentially toxic effects, and some are identified as either carcinogens or endocrine-disrupting chemicals or both (Hauser et al., 2007). Of these additives, phthalates raise many concerns for workers in the plastics industry (Gaudin et al., 2008; DeMatteo et al., 2012). In several countries, occupational atmospheric exposure limits for some phthalates particularly DEHP have been established, however, phthalates can also be inhaled, ingested and absorbed through the skin, therefore biological monitoring of phthalate metabolites is considered more suitable for assessing human exposure (Gaudin et al., 2011). The current acceptable exposure limit values for phthalates established by the EFSA (EFSA, 2005) are called tolerable daily intake (TDI) values for DEHP (50 $\mu \mathrm{g} / \mathrm{kg} / \mathrm{day})$, DiNP (150 $\mu \mathrm{g} / \mathrm{kg} / \mathrm{day})$, DnBP (10 $\mu \mathrm{g} / \mathrm{kg} / \mathrm{day})$. The US Environmental Protection Agency (US EPA) established reference dose (RfD) values for DEP ( $800 \mu \mathrm{g} / \mathrm{kg} / \mathrm{day})$, DnBP (100 $\mu \mathrm{g} / \mathrm{kg} /$ day), DEHP (20 $\mu \mathrm{g} / \mathrm{kg} /$ day) (EPA, 2008). Present studies demonstrate that urinary concentration of DEHP metabolites are significantly higher in occupationally exposed group than in general population (Gaudin et al., 2011). The aim of our study was to assess, by biological monitoring, occupational exposure to four phthalates of workers in plastic industry in comparison with general population.

\section{Method}

\section{Study Population}

The cohort consisted of two groups from Nitra region, Slovakia. Occupationally exposed population group $(n=37)$ i.e. workers from plastic manufactory with division of films and composites and injection moulding and general population ( $\mathrm{n}=$ 144), students and workers from Constantine the Philosopher University in Nitra in Nitra region of Slovakia. Participation was voluntary and there was a possibility to withdraw participation at any time during the study. All human participants gave written informed consent prior to the study, to provide samples of urine during the shift, complete questionnaires and allow the researchers to take measurements and also to process their personal records and data. The anthropometric data was collected using standard anthropological methods; body height (by A 319 TRYSTOM, Ltd., Pasteurova 15, 77200 Olomouc Czech Republic), waist girth and hip girth (by spreading calliper P-374 TRYSTOM, Ltd. Pasteurova 15, 77200 Olomouc Czech Republic). Body-mass index (BMI) was estimated and classified by WHO (1995). Waist-to-height ratio (WHTR) was calculated:

WHTR $=\frac{\text { waist circumference }(\mathrm{cm})}{\text { height }^{2}\left(\mathrm{~cm}^{2}\right)}$

Waist to hip ratio (WHR) was estimated by dividing the waist circumference by the hip circumference (WHO, 1986). Body weight were estimated by The Omron BF510 (Kyoto, Japan) by bio-electrical impedance analysis, using a $50 \mathrm{kHz}$ current source with electrodes on each hand and foot.

\section{Phthalates Analyses}

Urine samples $(2 \times 2 \mathrm{ml})$ were collected from all volunteers during work shift and from general population and stored in a transport box at $2-6^{\circ} \mathrm{C}$ and in the laboratory in a deep freezer at the $-73^{\circ} \mathrm{C}$ until analysis. Urinary levels of mono $(2-$ ethylhexyl) phthalate (MEHP), mono-n-butyl phthalate (MnBP), monoisononyl phthalate (MiNP), and monoethyl phthalate (MEP) as metabolites of parent phthalates di(2-ethylhexyl) phthalate (DEHP), di-n-butyl phthalate (DnBP), diethyl phthalate (DEP) and diisononyl phthalate (DiNP) were measured by high performance liquid chromatography (HPLC) and tandem mass spectrometry (MS/MS) (Infinity 1260 and 6410 triplequad, Agilent) using a modification of the method reported by Silva et al. (2003). Analytical standards were purchased from Cambridge isotope laboratories (MA, USA). Briefly, $1 \mathrm{ml}$ of urine was thawed, buffered with ammonium acetate, spiked with isotope labelled phthalate standards, $\beta$-glucuronidase enzyme (Roche, Germany) and incubated $\left(37^{\circ} \mathrm{C}\right)$. After deconjugation were samples diluted with phosphate buffer ( $\mathrm{NaH} 2 \mathrm{PO} 4$ in $\mathrm{H} 3 \mathrm{PO} 4$ ) and loaded on SPE cartridges (ABS Elut Nexus, Agilent). Cartridges were conditioned with acetonitrile followed by phosphate buffer before extraction. To remove hydrophilic compound were SPE cartridges flushed 
by formic acid and HPLC grade water. Elution of analytes was performed by acetonitrile and ethylacetate. Eluate was dried by nitrogen gas and reconstituted with $200 \mu \mathrm{l}$ of H2O. For HPLC was used Agilent Infinity 1260 liquid chromatograph equipped with ZORBAX Eclipse plus phenyl-hexyl column. Separation was done using non-linear gradient program. Agilent 6410 triplequad with electro-spray ionization was used for mass specific detection of phthalate metabolites. Instrumental settings were as follows: spray ion voltage $(-3800 \mathrm{~V})$, nitrogen nebulizer gas pressure (8 psi), and nitrogen curtain gas pressure $(7 \mathrm{psi})$, capillary temperature $\left(430^{\circ} \mathrm{C}\right)$, and collision gas (nitrogen) pressure $(1.5 \mathrm{mTorr})$. Precursor and product ions, collision energies, retention times and limits of detection (LOD) are showed in Table 1.

\section{Statistic}

To describe the urinary phthalate metabolite levels in the study populations, means with SD, medians and the 5th to 95th percentiles of concentrations were computed for each metabolite. The non-parametric Mann-Whitney U (Wilcoxon ranksum) test was used for all comparisons and a difference was considered to be significant when $p$ value was $\leq 0.05$. We used statistics program Statistica 8.0 (Stat Soft. Inc.).

\section{Results}

The cohort consisted of 181 participants of average age $31.66 \pm 14.53$ years. The cohort was divided into group of general population ( $n=144$; average age $28 \pm 13.12$ ) and occupationally exposed group i.e. workers from plastic manufactory with division of films and composites and injection moulding $(n=37$; average age 45.6 \pm 9.4$)$. The baseline characteristics of study groups are shown in Table 2.

Participants were also grouped according to questions asked in the extensive questionnaire to search for correlations with excreted amounts of phthalate metabolites. Within eating and drinking habits no significant differences were found. Distribution of the number of participants in both group following five consumer practise are shown in Table 3.

We found that urinary concentration of detected phthalate metabolites in occupationally exposed group was above the limit of detection (LOD) in $97.30 \%$ MEP, $100 \% \mathrm{MnBP}, 83.87 \%$ MiNP and 100\% in MEHP samples. In general population group LOD was exceeded in $96.53 \%$ MEP, $100 \%$ MnBP, $76.39 \%$ MiNP and 89.58 \% MEHP samples. Urinary concentrations of phthalate metabolites, characterized by means, SDs, minimum, maximum and percentiles in both groups, are summarized in Table 4. Mean concentration values for 3 urine metabolites (MEP, MnBP and MEHP) were higher in both groups than their median values, indicative of the high levels in the upper quantiles.

The comparison (Mann-Whitney $U$ test) between general population and occupationally exposed group for the urinary metabolite levels showed significantly higher urinary concentration $(p \leq 0.001)$ of MEHP and on the border of the statistical significance urinary concentration of MiNP $(p=0.07)$ in occupationally exposed group, while no significant differences could be seen for MEP and MnBP (Fig.1)

\section{Discussion}

Human exposure to phthalates classified like toxic hazardous substances can arise from both occupational and nonoccupational sources. Even though that occupational exposure to phthalates represents greater health risk for workers in plastic industry, occupational studies on potential associations with health risk is still limited. In our study, we present worker phthalate metabolite concentrations measured in 2012 in plastic factory, compare these concentrations to the general population in Nitra region of Slovakia and comment on the likelihood of an occupational contribution to the observed concentrations.

Urinary concentrations of MEHP in urine samples from exposed group (median $35.48 \mu \mathrm{g} / \mathrm{l}$ ) collected from all workers during work shift in our study are comparable with study of workers in a factory with wall covering products (median 41.9 $\mu \mathrm{g} / \mathrm{l}$ ), but higher than in workers in DEHP manufacturing (median $5.6 \mu \mathrm{g} / \mathrm{l}$ ), PVC 2 compounding (median $17.3 \mu \mathrm{g} / \mathrm{l}$ ) and polymers moulding (median $18.3 \mu \mathrm{g} / \mathrm{l}$ ). However they are lower than in plastisol coating (median $55.9 \mu \mathrm{g} / \mathrm{l}$ ) and PVC 1 compounding (median $52.0 \mu \mathrm{g} / \mathrm{l}$ ) (all of the above urine samples were collected post-shift) (Gaudin et al., 2011). In comparison with our previous study in workers from communal services (Kolena et al., 2014) median values in plastic industry was 7 -fold higher. The urinary concentration of MEHP in studied general population (median $21.62 \mu \mathrm{g} / \mathrm{l}$ ) was higher in comparison with control group from Gaudin et al. (2011) (median $4.8 \mu \mathrm{g} / \mathrm{l}$ ). We observed significantly higher urinary concentration of MEHP ( $p \leq 0.001)$ in occupationally exposed group compared to general 
population, despite the fact, that phthalates are ubiquitous environmental contaminants. This could be explained by the fact that DEHP is the major plasticizers of PVC used in plastic industry and after oral dosing in humans urinary excretion of DEHP metabolites is biphasic, with a first phase half-life of $2 \mathrm{~h}$ for all metabolites and a second phase half-life of $5 \mathrm{~h}$ for mono (2-ethylhexyl) phthalate (MEHP) (Koch et al., 2004; 2005). Therefore urinary concentrations of MEHP were expected higher in exposed group.

We observed on the border of the statistical significance higher urinary concentrations of MiNP $(p=0.07)$ in occupationally exposed group in comparison with general populations. Detected levels of MiNP in urine samples from exposed group (median $13.65 \mu \mathrm{g} / \mathrm{l}$ ) was higher with detection frequencies $83.8 \%$ in comparison with our previous study in communal services workers, wherein the concentration of MiNP was low and close to the detection limit, with detection frequencies of 10\% (median < LOD; 95th percentile $14.89 \mu \mathrm{g} / \mathrm{l}$ ) (Kolena et al., 2014).

Statistically significant differences was found only in high-molecular weight phthalates, which are predominantly used as a plasticizers in industry (Hauser \& Calafat, 2005).

The urinary concentration of $\mathrm{MnBP}$ in our study in exposed group (median $108.63 \mu \mathrm{g} / \mathrm{l}$ ) is comparable with the study of Becker et al. (2009) realised in German children, but higher than in workers in PVC compounding (median 22.6 $\mu g / l$ ) PVC film $(25.9 \mu \mathrm{g} / \mathrm{l})$ (Hines et al., 2009) and also with our previous results in communal services workers (median $67.13 \mu \mathrm{g} / \mathrm{l})$ (Kolena et al., 2014), and studies in general population of the USA, Germany and Japan (Blount et al., 2000; Koch \& Calafat, 2009; Itoh et al., 2007). In contrast with the results of Hines et al., (2009) realised in workers of phthalate manufacturing and rubber house at mid shift (median 230, $334 \mu \mathrm{g} / \mathrm{l}$ ) we recorded lover median values.

The urinary concentration of MEP in our study in exposed group (median $93.79 \mu \mathrm{g} / \mathrm{l}$ ) is comparable with workers in a rubber house at the end of shift (median $97.3 \mu \mathrm{g} / \mathrm{l}$ ). However they are lower than in other factories included at mid shift or at the end of shift (Hines et al., 2008). In contrast with the results of National Health and Nutrition Examination Survey (NHANES) by Blount et al., (2000) and Silva et al., (2004), we recorded in both group higher median concentration values of MEP. Use of personal care products with fragrances containing DEP (Duty et al., 2005) in the hours immediately before collecting of urine sample could affected higher urinary concentrations MEP in general population in our study.

Foodstuff represents the major source of exposure to high-molecular weight phthalates, such as di-(2-ethylhexyl) phthalate and diisononyl phthalate (DiNP) (Koch et al., 2006; Fromme et al. 2007), therefore we analysed some eating and drinking habits in comparison with concentrations of phthalate metabolites in each proband from both group. Interestingly we not found any statistically significant differences. It could be explained by single-spot urine sample which may not reflected the whole exposure of each participants. Furthermore, the great variability of phthalate metabolites excretion values within studies was likely due to individual physiological differences of each proband (Fong et al., 2014) or different quantity of phthalates used in each technology and factory. It suggest that habitual exposure of phthalate play minor role than occupational exposure, but it is necessary take this fact into account.

Our study has two important limitations. Single spot-urine measurement of phthalates during work shift may not necessarily reflect the long-term exposure of each participant. Exposure sources may vary over time based on dietary intake, use of personal care products and other factors. A second limitation of study is that we measured only simple monoesters of DEHP and DiNP in urine however oxidative metabolites are much more sensitive biomarkers of phthalate exposure. But despite this limitations and despite the fact that phthalates are ubiquitous environmental contaminants, there is evidence of occupational exposure of workers from plastic manufactory by DEHP a DiNP.

\section{References}

Blount, B. C., K. Milgram E., Silva, M. J., Milgram K. E., Silva M. J., Malek, N.A., Reidy, J. A., Needham, L. L., Brock, J. W. (2000). Quantitative Detection of Eight Phthalate Metabolites in Human Urine Using HPLC-APCI-MS/MS. Analytical Chemistry 72, 4127-4134.

Becker,K., Goen,T., Seiwert,M., Conrad,A. et al. (2009). GerES IV:phthalate metabolites and bisphenol A in urine of German children. Int.J.Hyg.Environ.Health 2009, 212,685-692.

David, R. M., Mckee, R. H., Butala, J. H. (2005). Esters of aromatic mono-, di-, and tricarboxylic acids, aromatic diacids, and di-, tri-, or polyalcohols. In: Bingham E, Cohrssen B, Powell CH, eds. Patty's toxicology. New York: John Wiley and Sons, 2001:635-932. 
DeMatteo, R., Keith, M. M., Brophy, J. T., Wordsworth, A., Watterson, A. E., Beck, M., Ford, A. R., Gilbertson, M., Pharityal, J., Rootham, M., Scott, D.N. (2012). Chemical exposures of women workers in the plastics industry with particular reference to breast cancer and reproductive hazards. New Solut. 2012; 22(4):427-448.

Duty, S. M., Calafat, A. M., Silva, M. J., Ryan, L., Hauser R. (2005). Phthalate exposure and reproductive hormones in adult men. In: Human Reproduction 20, 604-610 .

European Food Safety Authority (EFSA), (2005). Opinion of the Scientific Panel on Food Additives, Flavourings, Processing Aids and Materials in Contact with Food (AFC) on a request from the Commission related to Bis(2-ethylhexyl)phthalate (DEHP) for use in food contact materials. EFSA J. 243, 1-20.

EPA, Integrated Risk Information System (IRIS) (2008). Dibutyl phthalate (CASRN84-742),1990,(http://www.epa.gov/ncea/iris/subst/0038.htm); Di(2-ethylhexyl) phthalate (DEHP) (CASRN117-81-7),1993, (http://www.epa.gov/IRIS/subst/0014.htm);

2).1993.(http://www.epa.gov/iris/subst/0226.htm) US Environmental Protection Agency,12-1-2008.

Fong, J.P., Lee, F.J., Lu, I.S., Uang, S.N., Lee, C.C. (2014). Estimating the contribution of inhalation exposure to di-2ethylhexyl phthalate (DEHP) for PVC production workers, using personal air sampling and urinary metabolite monitoring. Int J Hyg Environ Health. 2014;217(1):102-109.

Fromme, H., Bolte, G., Koch, H. M., Angerer, J., Boehmer, S., Drexler, H., Mayer, R., Liebl, B. (2007). Occurrence and daily variation of phthalate metabolites in the urine of an adult population. International Journal of Hygiene and Environmental Health 210(1). 21-33.

Gaudin, R., Marsan, P., Robert, A., Ducos, P., Pruvost, A., Lévi, M., Bouscaillou, P. (2007). Biological monitoring of occupational exposure to di(2-ethylhexyl) phthalate: survey of workers exposed to plastisols. Int Arch Occup Environ Health. 2008 Aug;81(8):959-66.

Gaudin, R., Marsan, P., Ndaw, S., Robert, A., Ducos, P. (2011). Biological monitoring of exposure to di(2-ethylhexyl) phthalate in six French factories: a field study. Int Arch Occup Environ Health 84, 2011, 523-531.

Hauser, R., Calafat, A. M. (2005). Phthalates and human health. In: Occupational and enviromental medicine, 62, 2005, 806-818.

Hauser, R., Meeker, J.D., Singh, N.P., Silva, M.J., Ryan, L., Duty, S., Calafat, A. M. (2007) DNA damage in human sperm is related to urinary levels of phthalate monoester and oxidative metabolites. Human Reproduction 22, 688-695.

Heudorf, M., Mersch-Sundermann, V., Angerer, J. (2007). Phthalates: Toxicology and exposure. Hygiene and enviromental health, 210, 623-634.

Hines, C.J., Nilsen Hopf, N.B., Deddens, J.A., Calafat, A.M., Silva, M.J., Grote, A.A., Sammons, D.L.(2009). Urinary phthalate metabolite concentrations among workers in selected industries: a pilot biomonitoring study. Ann Occup Hyg. $2009 ; 53(1): 1-17$.

Itoh, H., Yoshida,K., Masunaga, S. (2007). Quantitative identification of unknown exposure pathways of phthalates based on measuring their metabolites in human urine. Environ. Sci.Technol. 2007, 41,4542-4547.

Koch, H. M., Angerer, J. (2007). Di-iso-nonylphthalate (DINP) metabolites in human urine after a single oral dose of deuterium-labelled DINP. In: International journal of hygiene and enviromental health, 210, 2007, 9-19.

Koch, H. M. - Bolt, H. M. - Angerer, J. (2004). Di(2-ethylhexyl)phthalate (DEHP) metabolites in human urine and serum after a single oral dose of deuterium-labelled DEHP. In: Archives of Toxicology, 78, 2004, 123-130.

Koch, H. M., Calafat, A. M. (2009). Human body burdens of chemicals used in plastic manufacture. In: Philosophical Transactions of the Royal Society B Biological science, 364(1526), 2009, s. 2063-2078.

Koch, H. M, Bolt, H. M., Preuss, R., Angerer, J. (2005). New metabolites of di(2-ethylhexyl) phthalate (DEHP) in human urine and serum after single oral doses of deuterium-labelled DEHP. Archives of Toxicology 79, 367-376.

Koch, H. M., Preuss, R., Angerer, J. (2006). Di(2-ethylhexyl) phthalate (DEHP): human metabolism and internal exposure - an update and latest results. International journal of andrology 29, 155-165.

Kolena, B., Petrovicova, I., Pilka, T. et al. Phthalate exposure and health-related outcomes in specific types of work environment. Int J Environ Res Public Health. 2014 May 26;11(6):5628-5639.

Loff, S., Hannmann, T., Subotic, U., Reinecke, F. M., Wischmann, H., Brade, J. (2008). Extraction of Diethylhexyl phthalate by Home Total Parenteral Nutrition From Polyvinyl Chloride Infusion Lines Commonly Used in the Home. Journal of Pediatric Gastroenterology and Nutrition, 47, 81-86. 
Silva, M. J., Barr, D. B., Reidy, J.A., Kato, K., Malek, N. A., Hodge, C. C., Hurtz III, D., Calafat, A. M., Needham, L. L., Brock, J. W. (2003). Glucuronidation patterns of common urinary and serum monoester phthalate metabolites. Archives of Toxicology 77, 561-567.

Silva, M. J., Reidy, J. A., Herbert, A. R., Preau, J. L., Needham, L. L., Calafat, A. M. (2004). Detection of phthalate metabolites in human amniotic fluid. Bulletin of Environmental Contamination and Toxicology 72. 1226-31.

World Health Organization (1986). Measuring obesity: classification and description of anthropometric data. Copenhagen: WHO; 1986.

World Health Organization (1995). Expert Committee on Physical Status: The use and interpretation of anthropometric physical status. WHO; 1995.

Wittassek, M., Wiesmüller G. A., Koch, H. M., Eckard, R., Dobler, L., Müller,J., Angerer, J., Schlüter, C. (2007). Internal phthalate exposure over the last two decades a retrospective human biomonitoring study. International Journal of Hygiene and Environmental Health, 210(3-4), 319-333.

Wittassek, M., Koch, H. M., Angerer, J., Brüning, T. (2011). Assessing exposure to phthalates-The human biomonitoring approach. Molecular Nutition\& Food Research 55, 7-31.

\section{Tables}

Table 1. Phthalate monoesters: chromatographic and mass spectrometric parameters

\begin{tabular}{lllllll}
\hline Compound Name & Precursor lon & Product lon & $\begin{array}{l}\text { Fragmentor } \\
(\mathrm{V})\end{array}$ & Collision Energy $(\mathrm{V})$ & $\begin{array}{l}\text { RT } \\
(\mathrm{min})\end{array}$ & LOD, $(\mu \mathrm{g} / \mathrm{l})$ \\
\hline MiNP & 291.2 & 141.2 & 95 & 13 & 15.2 & 8.12 \\
MiNP- labelled & 295.3 & 79 & 95 & 13 & 15.2 & \\
MEHP & 277.1 & 133.9 & 90 & 14 & 14.7 & 0.81 \\
MEHP- labelled & 281.1 & 137.1 & 90 & 14 & 14.7 & \\
MEP & 193.0 & 77.1 & 60 & 15 & 6.2 & 5.02 \\
MEP- labelled & 197.1 & 79.0 & 60 & 15 & 6.2 & \\
MnBP & 221.1 & 76.9 & 90 & 10 & 11.8 & 3.23 \\
MnBP- labelled & 225.1 & 78.8 & 90 & 10 & 11.8 & \\
\hline
\end{tabular}

Note: MiNP, monoisononyl phthalate; MEHP, mono (2-ethylhexyl) phthalate ; MEP, monoethyl phthalate; MnBP, mono-nbutyl phthalate; RT, retention time; LOD, limit of detection

Table 2. Baseline characteristic of study groups

\begin{tabular}{lllll} 
Parameter & General population & \multicolumn{2}{l}{ Exposed group } \\
\hline $\mathrm{n}$ & $\mathrm{n}=144$ & $\mathrm{n}=37$ & $\mathrm{SD}$ \\
& Average & $\mathrm{SD}$ & Average & 9.4 \\
\hline Age & 28.0 & 13.2 & 45.6 & 8.26 \\
Body height & 168.47 & 8.7 & 167.5 & 13.07 \\
Weight & 67.99 & 15.10 & 79.99 & 4.88 \\
BMl & 24.29 & 4.53 & 27.33 & 0.91 \\
WHR & 0.88 & 0.68 & 0.56 & 0.07 \\
WHTR & 0.49 & 0.08 & 0.56 & \\
\hline
\end{tabular}

Note: BMI, Body-mass index; WHR, waist to hip ratio; WHtR, waist-to-height ratio 
Table 3. Distribution of the number of participants in both group following five consumer practise (count/\%)

\begin{tabular}{|c|c|c|c|c|c|c|}
\hline Consumer practise & $n$ & yes & no & Always/usually & Sometimes & Never \\
\hline \multirow{2}{*}{$\begin{array}{l}\text { Drinking hot drink from } \\
\text { plastic cup during } 24 \\
\text { hour }\end{array}$} & 37 & $3(8.1)$ & 34 (91.9) & & & \\
\hline & 129 & $13(10.1)$ & $116(89.9)$ & & & \\
\hline \multirow{2}{*}{$\begin{array}{l}\text { Drinking drink from } \\
\text { plastic bottle during } 24 \\
\text { hour }\end{array}$} & 37 & $24(64.9)$ & $13(35.1)$ & & & \\
\hline & 126 & $109(86.5)$ & $17(13.5)$ & & & \\
\hline \multirow{2}{*}{$\begin{array}{l}\text { Heating food in plastic } \\
\text { container in microwave }\end{array}$} & 37 & & & $10(27.0)$ & $3(8.1)$ & $24(64.9)$ \\
\hline & 126 & & & $25(19.8)$ & $40(31.7)$ & $61(48.4)$ \\
\hline \multirow{2}{*}{$\begin{array}{lr}\text { Consumption } & \text { of } \\
\text { foodstuff in plastic } \\
\text { packaging }\end{array}$} & 37 & & & $10(27.0)$ & $14(37.8)$ & $13(35.1)$ \\
\hline & 125 & & & $33(26.4)$ & $77(61.6)$ & $15(12.0)$ \\
\hline \multirow{2}{*}{$\begin{array}{l}\text { Food stored in plastic } \\
\text { container }\end{array}$} & 37 & & & $10(27.0)$ & $13(35.1)$ & $14(37.8)$ \\
\hline & 126 & & & $50(39.7)$ & $59(46.8)$ & $17(13.5)$ \\
\hline
\end{tabular}

Table 4 Urinary concentration of phthalate metabolites $(\mu \mathrm{g} / \mathrm{l})$ in exposed group $(n=37)$ and general population $(n=144)$

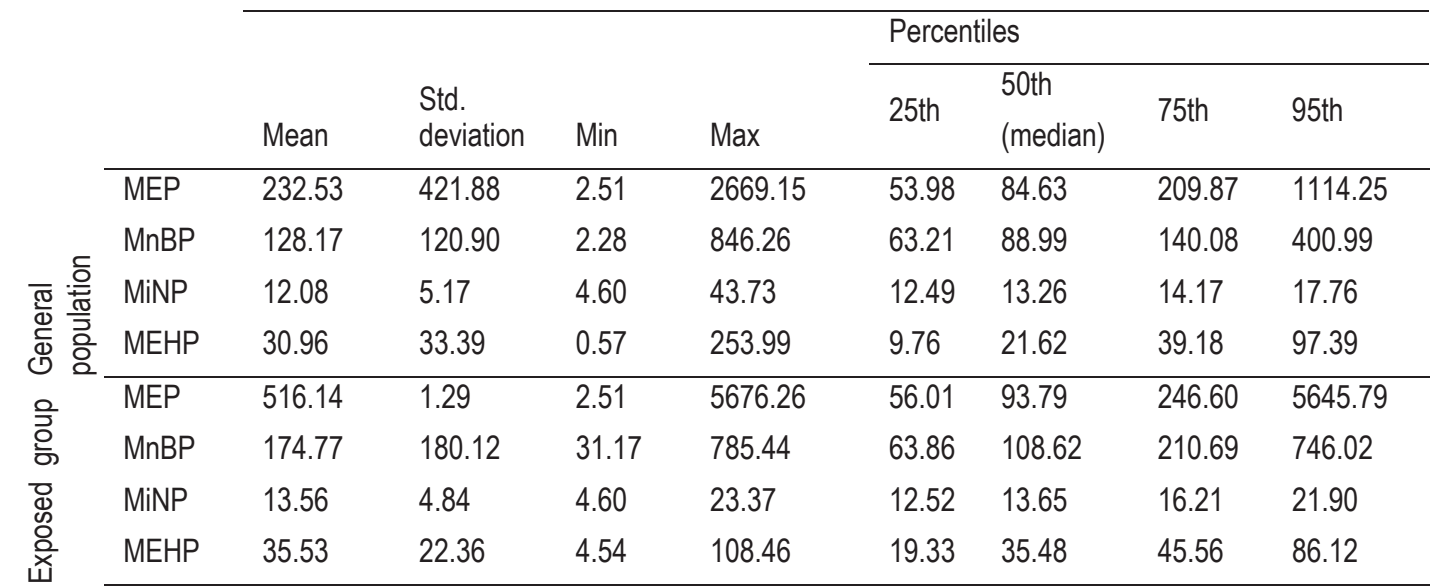

Note: MiNP, monoisononyl phthalate; MEHP, mono(2-ethylhexyl) phthalate; MEP, monoethyl phthalate; MnBP, mono-nbutyl phthalate 